This item was submitted to Loughborough's Research Repository by the author.

Items in Figshare are protected by copyright, with all rights reserved, unless otherwise indicated.

\title{
The provision of medical care in English professional football: an update
}

\section{PLEASE CITE THE PUBLISHED VERSION}

http://dx.doi.org/10.1016/j.jsams.2017.05.004

\section{PUBLISHER}

Elsevier @ Sports Medicine Australia

\section{VERSION}

AM (Accepted Manuscript)

\section{PUBLISHER STATEMENT}

This work is made available according to the conditions of the Creative Commons Attribution-NonCommercialNoDerivatives 4.0 International (CC BY-NC-ND 4.0) licence. Full details of this licence are available at: https://creativecommons.org/licenses/by-nc-nd/4.0/

\section{LICENCE}

CC BY-NC-ND 4.0

\section{REPOSITORY RECORD}

Malcolm, Dominic, Andrea Scott, and Ivan Waddington. 2017. "The Provision of Medical Care in English Professional Football: An Update”. figshare. https://hdl.handle.net/2134/25305. 


\section{Abstract}

2 Objectives: to compare the current methods of appointment, qualifications and occupational 3 experience of club doctors and physiotherapists in English professional football with (i) those outlined 4 in a study published in 1999, and (ii) Football Association (FA) medical regulations.

\section{Design: Qualitative}

6 Methods: Postal questionnaire survey of (head) doctors and physiotherapists at each of the clubs in the 7 English Premiership, Championship and Football Leagues 1 and 2. Response rates of 35.8\% and 45.6\% 8 respectively were obtained.

9 Results: The majority of football club doctors are GPs who have sports medicine qualifications and 10 relevant occupational experience. Time commitments vary from full time to a few hours per week. 11 Most are appointed through personal contacts rather than job advertisements and/or interview. Almost 12 all football clubs have a chartered physiotherapist, many of whom have a postgraduate qualification. 13 They work full time and long hours. Most are appointed through personal contacts rather than job 14 advertisements. They are frequently interviewed but not always by someone qualified to judge their 15 professional expertise.

16 Conclusions: Football club medical provision has become more extensive and increasingly 17 professional over the last 10-20 years, with better qualified, more career-oriented and more formally contracted staff. It is likely that clinical autonomy has subsequently increased. However recruitment

19 procedures still need to be improved, especially in relation to advertising vacancies, interviewing candidates, and including medical personnel on interview panels. In two aspects clubs appear not to

21 be compliant with current FA medical regulations.

\section{Keywords}

23 Football, club doctors, physiotherapists, qualifications, appointments 
In 1998/1999 the Professional Footballers Association (PFA) sponsored Waddington and colleagues to report on the provision of medical care in professional football in England. ${ }^{1}$ To our knowledge this was the first survey of its kind to be undertaken anywhere in the world and subsequently similar studies have only been undertaken in relation to English elite rugby union and British Olympic sports. $^{234}$ Based on a questionnaire survey of football club doctors and interviews with doctors, physiotherapists and players, the authors argued that selection and appointment procedures represented a 'catalogue of poor employment practice'. 5 The study also indicated that club doctors rarely had relevant occupational experience or specialist sport and exercise medicine (SEM) qualifications, and that they accepted what were generally poorly remunerated posts with no formal contracts simply because, in many cases, they were fans of the team. The report also revealed that a half of all 'physiotherapists' were not chartered and many held only the FA Diploma in the Treatment of Injuries. Many had no other medical occupational experience and were directly dependent on their personal relationship with the football club manager for their appointment. Under these conditions it was difficult for them to resist threats to their clinical autonomy and/or maintain ethical standards, ${ }^{67}$ which compromised players' trust in club medical teams. ${ }^{8}$

The report, which attracted considerable media (e.g. Daily Telegraph, 18/11/1999; Daily Star, 18/11/1999; Independent, 18/11/1999; Daily Mail, 19/11/1999; Guardian, 21/11/1999) and professional comment, ${ }^{9}{ }^{10}$ made ten recommendations related to the education, training and appointment of club medical personnel. Among them were that all vacancies should be publicly advertised; candidates should be formally interviewed; interview panels should include at least one independent medical practitioner; appointees should have written job descriptions; specialist sports medicine qualifications should be identified as desirable in club doctor person specifications, and clubs should assist employees to obtain them; clubs should develop a more professional medical service and move towards paying club doctors at recognised professional rates; all new physiotherapy appointees should be chartered while non-chartered 'physiotherapists' should only work under the 
supervision of a chartered physiotherapist; and club doctors should be fully involved in physiotherapy appointments. ${ }^{1}$

In the UK chartered physiotherapists are required to complete a degree in physiotherapy (approved by the Health Professions Council), while medical doctors require a degree in medicine (recognised by the General Medical Council), a two-year foundation programme, plus a period of specialist training, e.g. in general practice. 'Sport and exercise medicine' is a relatively new medical speciality in the UK, established in $2005,{ }^{11}$ the specialist training component of which lasts a minimum of six years. A number of postgraduate courses in SEM now exist and are desirable but not necessary for SEM speciality status.

Current Football Association (FA) medical regulations incorporate some of the recommendations of the PFA report. ${ }^{12}$ They specify that club doctors who began working in professional football post2003 must possess a Diploma in SEM (or equivalent), senior club physiotherapists should be chartered (although exceptionally clubs may employ a graduate sports therapist) and all non-chartered therapists should work under their supervision. While the FA issue regulations regarding CPD requirements these are unclear and/or inconsistent. Regulation 2.5 states that in the Premier League 'each therapist' (it is not clear whether 'therapist' includes doctors as well as physiotherapists) must undertake a minimum of 36 hours CPD per year (18 hours of which must consist of formally approved courses), while in the Football League there are no CPD requirements listed for physiotherapists but a stipulation that team doctors fulfil a CPD programme 'as determined by the profession' (regulation 3.4).

The research reported here examines the current methods of appointment, qualifications and occupational experience of club doctors and physiotherapists in English professional football. The analysis explores changes in English football since the earlier study, the degree to which current provision reflects the PFA report recommendations, and clubs' compliance with current FA medical regulations. 
77 Using materials adapted from the original study, a questionnaire (21 questions) was sent in January 2014 to a named club doctor at each of the 92 clubs in the English Premier and Football Leagues. Names of individuals were identified via websites or by telephoning clubs. Questionnaires contained mainly closed questions which explored the demographics, career background, working practices, appointment procedures and contractual basis of club doctors' roles. Thirty-three questionnaires were returned (a response rates of 35.8\%). Respondents were relatively evenly spread across the leagues. All were male and the majority of doctors were aged over $45.27 .3 \%$ of club doctors had been in post over 16 years (See Table 1).

\section{Table 1 about here}

In an enhancement to the previous study design, a comparable questionnaire (20 questions) was sent to a named physiotherapist at each of the 92 clubs. 42 questionnaires were returned (a response rate of 45.6\%). All but one respondent was male. Respondents were again drawn from across the leagues though there was a notable difference between responses from League 1 (highest response rate) and League 2 (the lowest). Physiotherapists were markedly younger than the doctors, with $85 \%$ under 45 years old (see Table 1), and physiotherapists working in lower leagues were the youngest of all (55\% of physiotherapists in Leagues 1 and 2 were under 35). Overall, 83.3\% had been in post for 10 or fewer years, but across the divisions the mean years of practice ranged from 8.0 in the Premiership to 3.3 in League 2.

Interviews were subsequently conducted with 8 doctors and 14 physiotherapists, although those data are not reported here. The study received full ethical approval from the appropriate university ethical advisory committee prior to data collection.

\section{Results}

\section{Doctors}



football club' as their primary source of employment (four from the Premiership, two from the

102 Championship) while three others (9.0\%) split their work between the club and other sports medicine practice. Outside of the Premiership 87.5\% of club doctors were GPs. However 63.6\% of respondents (but $88.8 \%$ of Premiership doctors) held a specialist SEM qualification. Over half (54.5\%) had previously worked for another football club or in another sport. 93.9\% had attended a sports medicine conference/CPD event in the previous 12 months.

All respondents were financially remunerated for their work with $60.6 \%$ receiving a salary, $30.3 \%$ invoicing for specific work and $21.2 \%$ paid a match attendance fee (ranging from $£ 150$ to $£ 500$ ). Salaried work was most common in the higher leagues. Payment was, however, not generally identified as a 'main reason' for acting as club doctor (cited by 21.2\%). Rather, the two most frequently cited motivations were a 'general interest in sport' (87.9\%) and 'occupational experience' (27.3\%). Over half of doctors in League 2 (57.1\%) also cited 'previously supported the team'.

$43.8 \%$ of club doctors have formal contracts. Only $9.7 \%$ had obtained their positions after responding to a public job advertisement (and these were mainly Premiership doctors), with 67.7\% obtaining their appointments through personal contacts with either the previous club doctor $(41.9 \%)$ or with a member of the coaching/committee staff (25.8\%). 'Other' routes (22.6\%) included being 'approached by the club's physiotherapist', 'FA recommendation', and being 'promoted' from crowd or academy doctor. $46.9 \%$ of football club doctors had been interviewed for their post. Surprisingly, League 1 doctors were most likely to have been interviewed (83.3\%). Only five of the 11 who provided details had been interviewed by a panel which included a medically qualified person.

There is considerable variety in the work routines reported by club doctors. All but one doctor attended first team home matches, while 39.4\% also attended reserve or youth team matches and 33.3\% travelled to first team away matches. $75.8 \%$ have scheduled surgeries at the club on non-match days,

124 the majority of whom (61.5\%) attend the club once or twice per week. While many (37.5\%) work fewer than 5 hours per week (hpw) at the club, 25\% of respondents attend between 11 and 20 hpw and 
126 a further $18.7 \%$ attend more than $20 \mathrm{hpw}$. The mean working time varied across the leagues from

$127 \quad 28.25$ hpw in the Premiership to 3.8 hpw in League 2.

128 Finally, doctors were asked to describe the make-up of the medical support teams that provided healthcare across all teams at their clubs. Clubs employed up to seven doctors (mean=2.33), eight physiotherapists (mean=3.7) and ten 'other' healthcare providers (mean=2.94). Size of medical support team followed the hierarchy of leagues with, for instance, an average of 2.9 doctors and 5.2 physiotherapists per Premier League club and 1.3 doctors and 1.5 physiotherapists per League 2 club.

Physiotherapists

$88.1 \%$ of the physiotherapists stated that they were chartered. Of the rest, three were physiotherapy graduates and two were sports therapy graduates. None stated that they held the FA Diploma in the Treatment of Injuries. 21.4\% had a postgraduate physiotherapy qualification, three-quarters of whom (77.8\%) worked in the Championship or League 1. 11.9\% had been awarded or were studying for a postgraduate diploma or MSc in Sport and Exercise Medicine. 85.7\% had relevant occupational experience with $80.5 \%$ having worked at another football club and 31.3\% in another professional/elite sport. 81.0\% had attended a sports physiotherapy conference/CPD course and 38.1\% a 'medical' conference/CPD event in the past 12 months. The most frequent attenders of training events were from Championship and League 1 clubs.

144 All respondents were paid a salary. The majority also received complimentary tickets (54.8\%) and/or expenses (52.4\%). Payment was the most frequently cited reason for acting as a football club physiotherapist (73.8\%), followed by 'general interest in sport' (69.2\%) and 'occupational experience' (35.7\%). Patterns of payment and motivations were relatively consistent across the leagues. three physiotherapists (31.0\%) had been recruited via a public job advertisement and, as in the case of club doctors, personal contacts were the central mechanism for recruitment; $35.7 \%$ had obtained their 
post through personal contact with a club doctor or physiotherapist and $16.7 \%$ through personal contact with a coach or committee member. A further $16.7 \%$ obtained their post through 'other' means (including being a former player, being promoted from academy physiotherapist and recruited through an agency). $88.1 \%$ had been interviewed, $51.4 \%$ by a panel that included the 'head of medicine' or club doctor and a further $8.1 \%$ by a panel including a physiotherapist. Appointment procedures, interviews etc. were relatively consistent across the leagues.

All but one physiotherapist attended first team home matches and all but two attended first team away matches. 23.8\% also attended reserve or youth matches. All but one respondent attended the club on non-match days. The mode number of non-match days worked per week was five (75.6\%). Most physiotherapists (54.8\%) estimated that they typically work between 50 and 60 hpw but almost 10\% stated that they worked in excess of this. Estimated mean working hours were highest in the Premiership (55.7 hpw).

\section{Discussion}

The response rates for the two surveys reported here were lower than that in the earlier research (64.4\%). ${ }^{1}$ This might be explained by: a) the inaccuracy of information derived from websites; b) the absence of a sponsoring organisation such as the PFA to add legitimacy to the survey; and/or c) the negative publicity about the quality of medical provision in football which stemmed from the previous study. However response rates were within the normal range for a postal questionnaire, ${ }^{13}$ and the distribution of respondents across the various leagues suggests that the sample is broadly representative of the population surveyed. The information on football club physiotherapists generated in this study has greater reliability and validity than that previously available.

173 It is clear that there have been a number of significant improvements in several aspects of medical 174 provision since the earlier study was undertaken. In particular, there has been a substantial improvement in the qualifications and experience both of club doctors and physiotherapists. Many more club doctors now have specialist SEM qualifications and have relevant occupational experience 
177 (see Table 2). Reliance on the FA Diploma for the Treatment of Injuries, held by 23 of the 53 club

178 physiotherapists in the earlier study, is now a thing of the past.

179

Table 2 about here

There is also evidence of the development of sports medicine as a career path, with formal contracts issued more frequently and more positions in football providing doctors with their primary employment. While the earlier study found that the club doctor was typically a 'one sport, one club doctor' and that their 'commitment is typically not to sports medicine in general but to their local club’, ${ }^{5}$ many current doctors had worked for multiple clubs and/or multiple sports, and relatively few identified 'support for the team’ as a primary motivation to become club doctor. Payment of doctors is more widespread than in the past. In sum, clubs have moved towards a more professional provision of medical support and the personnel employed show a greater commitment to sports medicine as a career. Clubs in the higher, more affluent, leagues have the most professional and extensive medical provision. To some extent this reflects recent changes in SEM in Britain more broadly. ${ }^{3411}$

These changes are likely to have a qualitative impact on medical care. The increase in the number of hours doctors spend on football club work, combined with their less frequent attendance at reserve and youth matches, suggests that doctors' time is increasingly spent providing ongoing treatment to players rather than emergency cover at games. The number of physiotherapists who had been in post for over three years (61.9\%) suggests that many retain their positions for longer and therefore enjoy greater job security than most managers. While we do not have directly comparable data from the PFA survey, it seems clear that clubs currently employ more doctors, physiotherapists and other sports science/healthcare staff.

However it is also clear that many aspects of the appointment process still fall short of good employment practice. The vast majority of club doctor posts are still not publicly advertised, with fewer than $10 \%$ of doctors indicating that they obtained their post as a result of responding to a public advertisement. It is still the case that the majority of doctors obtain their posts as a result of personal contact with either the former doctor or someone else at the club. And although interview panels are 
now more likely to contain a person with a medical qualification, this is not universal and the number of doctors interviewed for their post has actually fallen since 1999. The degree to which the sample as a whole remains overwhelmingly male is indicative of the lack of change and that professional football remains an unwelcoming environment for females.

Aspects of poor employment practice can also still be identified in the appointment process for club physiotherapists. The earlier research found that physiotherapists had largely been recruited through informal channels or an 'old boy's network', and the position was frequently 'in the gift of the manager' ${ }^{5}$ Just $10 \%$ of interviewees in the PFA report had obtained their post after responding to a public job advertisement. The present study indicates that there has been some, but limited, progress in this regard. As noted, although 31\% were recruited as a result of responding to a public advertisement, more than half had obtained their posts as a result of personal contact with either a member of the club's medical team or a coach or committee member. Just over half had been interviewed by a panel that included the club doctor. In contrast to club doctors, the working conditions and practices of physiotherapists is relatively standardised across leagues.

Two findings lead us to question the degree to which clubs conform to current FA medical regulations. Although, FA regulations are unclear regarding CPD requirements, the limited CPD undertaken by some respondents is a cause for concern. One physiotherapist and two doctors indicated that they had attended no such training in the past year. Additionally, five physiotherapists cited a single event (frequently the one-day FA Advanced Resuscitation and Emergency Aid course).

More unequivocally, and perhaps more worryingly, our research revealed three doctors working with clubs in the Championship and Football League 2 who had been appointed since 2003, but who did not possess a Diploma in SEM or equivalent. One of these had worked at another Football League club so may comply with FA medical regulations, but the other two had not and thus appear to be in breach of FA regulations. These findings suggest an absence of effective monitoring by the FA of its own regulations. 
While some of the policy recommendations of the PFA report have effectively been implemented others have not. The number of club doctors without specialist SEM qualifications (and despite having been in post for over a decade) suggests that many clubs are not assisting their employees to obtain essential qualifications. While physiotherapists are employed on a formal contractual basis, the majority of club doctors are not. Vacancies are still not routinely advertised, candidates are often not formally interviewed and interview panels only sometimes contain medical personnel (whether independent or not). Indeed only about a quarter of all club doctors are appointed having been interviewed by someone qualified to assess their medical expertise. The recommendations of the earlier report that have been most completely implemented (those relating to formal qualifications) are those adopted in current FA medical regulations.

\section{Practical Implications}

To ensure greater regulatory compliance the FA should:

- clarify existing regulations, particularly as they relate to CPD

- incorporate the outstanding recommendations of the 1999 PFA report

- implement an effective monitoring programme.

These developments would enable further improvements to medical provision in the game.

246 All professional sports leagues should consider conducting similar, independent, audits and monitor medical provision to ensure that clubs meet best practice and compliance with any regulations.

\section{Acknowledgements}

249 The authors alone are responsible for the content and writing of this article and did not receive financial assistance to undertake the research

\section{References}


${ }^{1}$ Waddington I, Roderick M, Parker G. Managing Injuries in Professional Football: the Roles of the Club Doctor and Physiotherapist. Centre for Research into Sport and Society, University of Leicester, 1999.

${ }^{2}$ Malcolm D, Sports medicine: a very peculiar practice? Doctors and physiotherapists in elite English rugby union. In I. Waddington, B. Skirstad and S. Loland (Eds.) Pain and Injury in Sport. Social and Ethical Analysis. London: Routledge.

3 Malcolm D, Scott A. Professional relations in sport healthcare: workplace responses to organisational change. Social Science and Medicine 2011,72;513-520.

${ }^{4}$ Malcolm D, Sport, Medicine and Health: the Medicalization of Sport. London: Routledge.

${ }^{5}$ Waddington I, Roderick M, Naik R. Methods of appointment and qualifications of club doctors and physiotherapists in English professional football: some problems and issues. Br Jo Sports Med 2001;35: 48-53.

${ }^{6}$ Waddington I. Sport, Health and Drugs: a Critical Sociological Perspective. London: E\&F Spon, 2000, 59-86.

${ }^{7}$ Waddington I, Roderick, M. The management of medical confidentiality in English professional football clubs: some ethical problems and issues. Br Jo Sports Med 2002;36: 118-123.

${ }^{8}$ Roderick M, Waddington I, Parker, G. Playing hurt: managing injuries in English professional football. Int Rev for the Soc of Sport, 2000;35: 165-180.

${ }^{9}$ Mackay, R. Club doctors and physiotherapists, Br Jo Sports Med 2001;35: 207

${ }^{10}$ Boyce, S. The football club doctor system, Br Jo Sports Med 2001;35: 281

${ }^{11}$ Batt M, Cullen M. Sport and exercise medicine in the United Kingdom comes of age. Br Jo Sports Med 2005,39;250-251

${ }^{12}$ FA (2014) Rules and Regulations of the Association. Season 2014-15. Football Association London, 2014.

${ }^{13}$ May, T. Social Research: Issues, Methods and Process. Buckingham: OUP, 2001. 
